\title{
Examining Effectiveness of m-Learning in Hospitality Education with Revised Technology Acceptance Model
}

\author{
Liwei Hsu and Chia-wen Chen
}

\begin{abstract}
This study explored the effectiveness of using mobile devices in the learning of hospitality subjects. Four hundred and thirty-seven (437) high school students in a hospitality program in Taiwan participated in this survey and the revised technology acceptance model (TAM) was adopted as the major research instrument. Seven research hypotheses were posited. The results of statistical analysis indicated that participants regarded perceived ease of use (PEU) as being more important than perceived usefulness (PU) when M-Learning (a combination of mobile device and e-learning) is designed to be integrated in teaching and learning hospitality subjects. Five of the seven research hypotheses were supported by the structural equation model (SEM). Specifically, this study found that the genre of courses (academic course and practical course) did not significantly lead to either PEU or PU but it resulted significantly in participants' having different behavioral intention to use (IU) M-Learning. Moreover, PEU as well as PU were significantly related to IU. Counterintuitively, IU has a significantly negative effect on the effectiveness of self-learning.
\end{abstract}

Index Terms-Hospitality education, m-learning, revised technology acceptance model, structural equation model.

\section{INTRODUCTION}

Concomitant with the rapid development of information and communication technology (ICT), the application of mobile devices in various activities of daily life has become increasingly prevalent. With the affordance of convenience, expediency, and immediacy, mobile devices are also being exploited in educational settings [1]. Thus, M-Learning, the integration of mobile devices and e-learning, has grown in importance, with increased attention being given by scholars and practitioners [2], [3]. Previous studies [4]-[7] have pointed out the advantages that M-Learning may bring forth in students' learning. Nevertheless, more empirical evidence is still needed to extend our understanding of the effectiveness of M-Learning. To explore the psychological constructs of the factors that influence learners' learning effectiveness in an M-Learning context, the Technology Acceptance Model (TAM) is predominantly adopted as the research model by empirical studies [8]-[10]. TAM contains constructs such as perceived usefulness (PU), perceived ease of use (PEU), and intention to use (IU) that it employs to explore learners' attitude toward M-Learning. However, the original TAM has been criticized as being inadequate by

Manuscript received January 12, 2018; revised March 29, 2018. This work was supported in part by the Ministry of Science and Technology (MOST 103-2511-S-328-001-MY2).

The authors are with the National Kaohsiung University of Hospitality and Tourism, Kaohsiung City, Taiwan (e-mail: liweihsu@mail.nkuht.edu.tw). scholars such as Tarhini et al. [11]. Consequently, a revised TAM was proposed to better fit the real situation. The major difference between these two models is the external factors that may influence other variables of TAM and users' attitude or intention to use a specific technology. Previous research on TAM reported that the variables PEU and PU are significantly correlated because end-users are keen to use technologies for either enjoyment or usefulness [12], and such results have inspired many follow-up studies that have given to mixed results [13].

Approximately $10 \%$ of the global workforce is employed in the hospitality industry. Thus, the training and education of prospective professionals of this industry deserve more attention [14]. Specifically, hotel employees with proper training would have a positive influence on stakeholders such as the employees themselves, hotels, and guests [15]-[17]. Thus, the studies cited above have indicated the necessity of providing sufficient and proper training and education to future employees of the hospitality industry.

In Taiwan, the curriculum of the hospitality program at the secondary education level contains three tracks; namely, general education courses such as Hospitality English and Conversation, academic courses such as Introduction to Hospitality and Hotel and Restaurant Service, and practical courses such as Beverage and Cocktail Preparation [18]. These three tracks should be abreast of each other for prospective employees in the hospitality industry. In terms of pertinent research, numerous empirical studies have discussed the application of technology in hospitality education. To the best our knowledge, the use of different genres of hospitality courses as external factors in TAM has never been studied. Thus, this current study may be the first to explore the possible relationship between variables.

\section{METHOD}

\section{A. Proposed Model and Research Hypotheses}

As discussed above, this present study adopted revised TAM [12] as the research model wherein two genres of hospitality courses (academic course and practical course) were used as the external factors of TAM to examine the structural relationships of all variables. The proposed research model is depicted in Fig. 1.

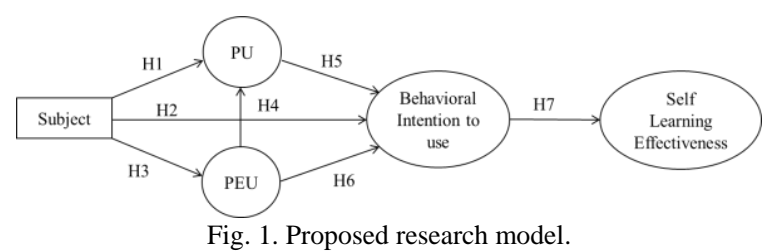


On the basis of the proposed research model, we posit the seven research hypotheses outlined below.

H1. Different genres of hospitality courses have a significant effect on the PU of M-Learning.

H2. Different genres of hospitality courses have a significant effect on learners' intention to use M-Learning.

H3. Different genres of hospitality courses have a significant effect on the PEU of M-Learning.

In terms of the remaining variables of TAM, some studies postulate that PEU may significantly influence PU [19], whereas the results of other studies do not support such a claim [20], [21]. Therefore, it is noteworthy to extend our current understanding on the association of these two variables, particularly in the context of using M-Learning in hospitality courses. Thus, further hypotheses on the effect of PEU on PU and how both variables affect hospitality students' intention to use M-Learning were posited in this study. Considering the applicability and usability of M-Learning in promoting students' self-learning, the results of a prior study by Wang [22] affirmatively support this statement. Nevertheless, pertinent research on the effectiveness of using M-Learning in hospitality courses for students' self-learning is still lacking, which necessitates the seventh research hypothesis posited in this study.

Hypotheses 4 to 7 are as follows:

H4. Hospitality students' PEU has a significant effect on the PU of M-Learning.

H5. Hospitality students' PU has a positive effect on their intention to use M-Learning.

H6. Hospitality students' PEU has a positive effect on their intention to use M-Learning.

H7. Hospitality students' intention to use M-Learning has a positive effect on their self-learning effectiveness.

\section{B. Research Context}

The experimental M-Learning courses developed and designed for this current study were provided by a private high school in Kaohsiung City, Taiwan. The courses were integrated as complementary self-learning materials for the traditional in-class teaching that began in September 2016 for a period of four months. Students who joined this experimental program were given an HTC Flyer tablet computer as a learning tool. The M-Learning courses included three major contents: text (usually the handout of each unit in either PowerPoint or PDF file), video clips, and discussion board. The survey was conducted in February of 2017.

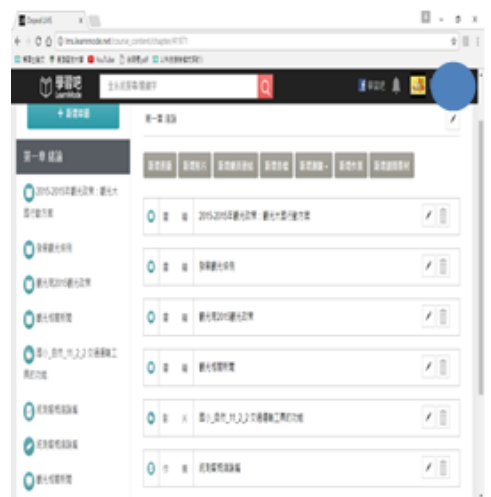

Fig. 2. Screenshot of m-learning (academic courses).

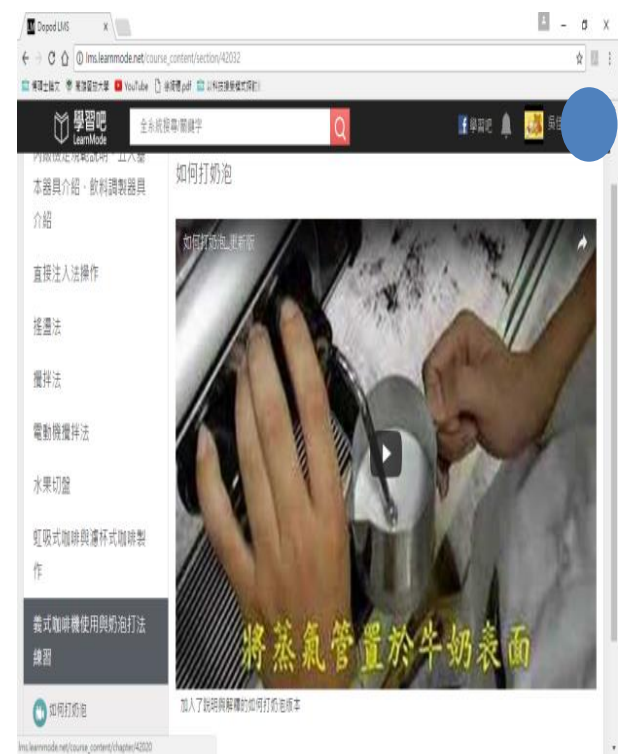

Fig. 3. Screenshot of m-learning (practical course).

\section{Participants and Instrumentation}

Of 570 students of a private high school in Taiwan invited to participate in this study, $437(n=437)$ successfully completed the courses and turned in valid questionnaires - a response rate of $97.1 \%$. Participation in the study was wholly voluntary and, as all the participants were minors, permission was first obtained from their legal guardians. Of the 437 participants, 241 of (55\%) were males, 196 were females $(45 \%)$, and the average age was 19.6 years.

The main research instrument was the TAM questionnaire developed by Davis et al. [23] and Szajna [24]. Questionnaire items associated with PU comprised six questions (e.g., "Using M-Learning would help me learn the target contents by myself”') and participants' PEU was measured via six questions (e.g., "It is easy for me to use the M-Learning materials to learn the target contents"). Six questions were designed to elicit answers from participants regarding their intention to continue using M-Learning to learn the subject matter in the hospitality courses (e.g., "I would love to use M-Learning to learn the target contents of the hospitality courses"), and their self-learning effectiveness was investigated via six questions (e.g., "I think M-Learning enables me to acquire the target knowledge/skills effectively"). All of the questionnaire items were measured on a Likert 5-point scale, where $1=$ completely disagree and 5 = completely agree. Following development of the questionnaire, a panel of five experts (three professors of instruction technology and two senior teachers of hospitality programs in high schools) were invited to review all of the questions to ascertain their propriety in terms of wording and logic. Some modifications were subsequently undertaken in accordance with their advice. Cronbach's alpha and Confirmatory Factor Analysis were also performed to ensure the reliability and validity of this research instrument - the results are presented in Table I.

The results of analysis of the data displayed in Table I indicated that the questionnaire items met the threshold of reliability and validity. In other words, the research instrument was appropriate for use in the study to elicit the participants' responses to the constructs of TAM. 
TABLE I: RELIABILITY AND VALIDITY OF QUESTIONNAIRE ITEMS

\begin{tabular}{|c|c|c|c|c|c|}
\hline Construct & $\begin{array}{l}\text { Construct } \\
\text { Code }\end{array}$ & $\begin{array}{l}\text { Item } \\
\text { Loading }\end{array}$ & AVG. & $\mathrm{CR}$ & $\begin{array}{l}\text { Cronbach } \\
\alpha\end{array}$ \\
\hline Perceived & PEU1 & 0.68 & & & \\
\hline \multirow[t]{5}{*}{ Ease of Use } & PEU2 & 0.60 & & & \\
\hline & PEU3 & 0.73 & 0.52 & 0.86 & 0.95 \\
\hline & PEU4 & 0.70 & & & \\
\hline & PEU5 & 0.75 & & & \\
\hline & PEU6 & 0.68 & & & \\
\hline Perceived & PU1 & 0.91 & & & \\
\hline \multirow[t]{5}{*}{ Usefulness } & PU2 & 0.86 & & & \\
\hline & PU3 & 0.50 & 0.59 & 0.89 & 0.90 \\
\hline & PU4 & 0.80 & & & \\
\hline & PU5 & 0.61 & & & \\
\hline & PU6 & 0.53 & & & \\
\hline Intention to & IU1 & 0.87 & & & \\
\hline \multirow[t]{5}{*}{ Use } & IU2 & 0.82 & & & \\
\hline & IU3 & 0.73 & 0.50 & 0.84 & 0.95 \\
\hline & IU4 & 0.65 & & & \\
\hline & IU5 & 0.60 & & & \\
\hline & IU6 & 0.46 & & & \\
\hline Self-Learning & SLE1 & 0.90 & & & \\
\hline \multirow[t]{5}{*}{ Effectiveness } & SLE2 & 0.89 & & & \\
\hline & SLE3 & 0.88 & 0.51 & 0.86 & 0.90 \\
\hline & SLE4 & 0.87 & & & \\
\hline & SLE5 & 0.83 & & & \\
\hline & SLE6 & 0.82 & & & \\
\hline
\end{tabular}

\section{RESULTS}

Descriptive statistics show that the participants gave a higher score to PEU $(M=4.33)$ than PU $(M=4.30)$, which indicates that PEU would be more important than PU when M-Leaning is designed to be integrated into teaching and learning. Participants' intention to use M-Learning was lowest $(\mathrm{M}=4.27)$, whereas the mean score of participants' viewpoint of the self-learning effectiveness of M-Learning was 4.29 on the 5-point scale. The details of the descriptive statistics are presented in Table II.

TABLE II: DESCRIPTIVE STATISTICS OF CONSTRUCTS (N=437)

\begin{tabular}{lcc}
\hline Construct & Mean & Standard Deviation \\
\hline PEU & 4.33 & 0.69 \\
PU & 4.30 & 0.67 \\
IU & 4.27 & 0.62 \\
SLE & 4.29 & 0.65 \\
\hline
\end{tabular}

In terms of the participants' PU when M-Learning was used in the practical course compared to the academic course, the $t$-test showed a significant difference $(t=-3.22, p<0.00)$, with similar results PEU $(t=-2.33, p<0.05)$. In other words, participants perceived that the usefulness and ease of use of M-Learning were different for different genres of courses.

To explore the structural relationship among the proposed constructs, the structural equation model (SEM) is usually adopted by researchers to depict the holistic causal relationship between constructs. The SEM is presented in Fig. 4 (Note: $\mathrm{CMIN} / \mathrm{DF}=3.033, \mathrm{GFI}=0.87, \mathrm{AGFI}=0.83, \mathrm{CFI}=$ $0.90, \mathrm{IFI}=0.90$, RMSEA $=0.07$ ).

The results of SEM showed that five of these seven research hypotheses were supported. Further, it reported that different classes did not significantly affect either PEU or PU, but significantly led to different behavioral intention to use M-Learning (path coefficient $\beta=-0.07, p=<0.00$ ). It revealed an interesting phenomenon, participants were more interested in using M-Learning in the academic course (in this case, the course was Introduction to the Food and Beverage Industry). Moreover, PEU had a significant effect to PU (path coefficient $\beta=0.41, p=<0.00$ ) and both PEU and PU had a significant effect on participants' IU (path coefficient $\beta=0.13$ and 0.08 , respectively). Counterintuitively, IU had a significant negative effect on participants' self-learning effectiveness. Table III summarizes the results of hypothesis testing with SEM.

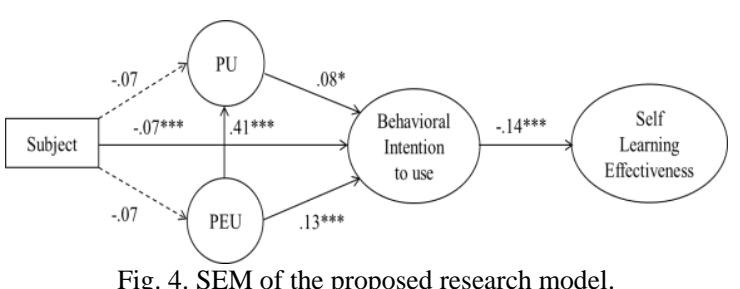

Fig. 4. SEM of the proposed research model.

TABLE III: SUMMARY OF THE RESULTS OF HYPOTHESIS TESTING WITH SEM

\begin{tabular}{llccc}
\hline & Hypothesis & B & p-value & Supported \\
\hline H1 & PU $\leftarrow$ Subject & -0.07 & 0.29 & No \\
H2 & IU $\leftarrow$ Subject & -0.07 & 0.23 & No \\
H3 & PEU $\leftarrow$ Subject & -0.07 & $* * *$ & Yes \\
H4 & PU $\leftarrow$ PEU & 0.41 & $* * *$ & Yes \\
H5 & IU $\leftarrow$ PU & 0.08 & $*$ & Yes \\
H6 & IU $\leftarrow$ PEU & 0.13 & $* *$ & Yes \\
H7 & SLE $\leftarrow$ IU & -0.14 & $* * *$ & Yes \\
\hline Note: $* p<0.05, * * p<0.01, * * * p<0.001$ & &
\end{tabular}

\section{DISCUSSION}

The expedient development of mobile technology has changed the landscape of education, with hospitality education being no exception [25]. The easy availability of mobile devices has enabled students to access learning materials without limitations in time and space [26]. The major advantage of M-Learning in education is that it aids students' self-learning [27]. Thus, it has gradually become an innovative way of learning [28]. However, empirical evidence regarding hospitality students' acceptance of M-Learning is still needed.

The descriptive statistics elicited by this study indicate that hospitality students will consider PEU to be more important to them than PU when M-Learning is integrated as part of a course. Further analysis of the different viewpoints of hospitality students on PEU and PU of M-Learning when the genre of courses was used as the independent variable and t-test showed that a significant difference exists.

Because a significant difference resulting from the genre of subject matter was discovered in participants' PEU and PU of M-Learning, further analysis was performed using other variables of TAM and SEM and the structural relationship of subject matter as an external variable. The results from SEM showed that the subject did not have a significant effect on either PEU or PU. Nevertheless, it did significantly affect participants' intention to use M-Learning. Possible reasons for these results may include the fact that hospitality students had difficulty understanding how different subjects affect their PEU and PU of M-Learning, even though they knew the differences. Further, the design of the questionnaire items may be another reason as the subjects were discerned in 
dichotomy $(1=$ academic course and $2=$ practical course $)$. It is advisable that future studies use a more sophisticated or better-defined method of differentiation. Designing a qualitative study (e.g., interview) to acquire more in-depth information from the participants may also facilitate the acquisition of important data that are not obtainable via quantitative studies.

Different subjects were found to have a significant effect on the hospitality students' intention to use M-Learning; specifically, they were keener to use M-Learning to learn the academic course. This could be attributed to the fact that the students would be better off being taught the practical course within the real or authentic context where they can practice the acquired skills in real time. If the future design of M-Learning included virtual reality (VR) technology that enabled students to practice the skills that they acquired through M-Learning, the possibility that students would use M-Learning for the practical course would be higher.

Regarding the effect that PEU would lead to PU, this present study echoes the findings of previous studies [29]-[31] that explicitly reported that PEU positively and significantly influences PU. Both PEU and PU have a significant effect on the hospitality students' intention to use M-Learning. The effect that PU has on IU has been addressed in prior academic research [32], [33], but how PEU affects IU remains controversial in academia as, whereas several scholars [23] posit that PEU has a significant effect on IU, others [11] disagree. The results of this study showed that for hospitality students, the PEU of an M-Learning course would have a significant effect on their intention to use M-Learning. On the basis of this finding, we suggest that when designing an M-Learning hospitality course, ease of use should not be overlooked by the course designers and programmers.

The last hypothesis examined the effect of participants' IU on their self-learning effectiveness, which was not supported by the data we retrieved. In other words, the more hospitality students intended to use M-Learning, the less self-learning effectiveness they perceived. Such a result is not in line with Chauhan's study [34], which discovered a positive relationship between participants' IU and self-learning effectiveness. One possible explanation is that M-Learning is very new to most hospitality students, who probably are not familiar with the idea of using mobile devices for learning, even though they use them daily. Another explanation is based on the participants' cultural background: Asian students are still familiarizing themselves with the learner-centered method of learning; thus, they are probably unsure of whether their self-learning is effective. It is easy for them just use academic performance to define self-learning effectiveness and disregard other factors such as motivation and confidence.

\section{CONCLUSIONS AND IMPLICATIONS}

This study extends our current understanding of the applicability of using M-Learning in two types of hospitality courses-academic course and practical course. Descriptive statistics showed that the participants in this study considered the PEU of M-Learning as the most important variable, followed by PU. When the genre of courses is taken into consideration, significant differences are shown, which indicates that when hospitality students use M-Learning, course genres do influence their thoughts on the importance of PU and PEU.

The results of SEM indicate that neither the academic course nor the practical course has a significant effect on PEU or PU; however, the difference does have a significant effect on their intention to use M-Learning. In terms of the structural relationship between the variables of TAM, PEU has a significant effect on PU and both PEU and PU are significantly and positively associated with hospitality students' intention to use M-Learning. However, their intention to use M-Learning has a significantly negative effect on their self-learning effectiveness.

The implications of the findings of the present study for practitioners is as follows. Firstly, it is advisable that the contents and design of M-Learning for hospitality courses should pay close attention to the usefulness and ease of use of the materials intended to be delivered, even though course type does not have a significant effect on PEU or PU. PEU is significantly leading to PU, which means that if hospitality students perceive an M-Learning course as easy to use, they will tend to consider it to be useful. PEU also has a greater effect on their intention to use M-Learning than PU. Therefore, PEU of M-Learning should be the primary concern when designing the M-Learning. Hospitality students' intention to use M-Learning has a negative effect on their self-learning effectiveness; hence, practitioners are encouraged to teach learners various strategies to help them familiarize themselves with this innovative way of learning in order to optimize their self-learning effectiveness [32].

Finally, based on the limitations of this study, this paper puts forth the following suggestions for future research. Firstly, this current study was undertaken at a vocational high school in Taiwan where the Confucius method of pedagogy is still the main teaching and learning ideology. Learner-centered pedagogy may be foreign to the teachers and learners: therefore, the generalizability of this model may be limited to similar contexts. In addition, a qualitative study with interviews may elicit more detailed information about each participant's own thoughts on the applicability of M-Learning. Finally, considering other variables of the revised TAM, such as subject norm, image, job relevance, output quality, and result demonstrability, as the direct antecedent predictor in the model would be a productive direction for future research.

\section{REFERENCES}

[1] H. Kynaslahti, "In search of elements of mobility in the context of education," in Professional Mobile Learning, H. Kynaslahti and P. Seppala (Eds.), Helsinki, Finland: IT Press, 2003, pp. 41-48.

[2] A. Bozkurt, "Augmented reality with mobile and ubiquitous learning: Immersive, enriched, situated, and seamless learning experiences," Digital Tools for Seamless Learning, IGI Global, 2017, pp. 27-41.

[3] C. H. Lai, J-C. Yang, F-C. Chen, C-W. Ho, and T.-W. Chan, "Affordances of mobile technologies for experiential learning: The interplay of technology and pedagogical practices," Journal of Computer Assisted Learning, vol. 23, no. 4, pp. 326-337, 2007.

[4] M. Al-Emran, H. M. Elsherif, and K. Shaalan, "Investigating attitudes towards the use of mobile learning in higher education," Computers in Human Behavior, vol. 56, pp. 93-102, 2016.

[5] M. D. Duprey, A. Hutchings, and A. H. Mamishian. (2016). Promoting student engagement through the use of mobile applications. [Online]. 
Available:

http://vhl.aws.openrepository.com/vhl/handle/10755/620612

[6] F. K. Chiang, G. Zhu, Q. Wang, Z. Cui, S. Cai, and S. Yu, "Research and trends in mobile learning from 1976 to 2013: A content analysis of patents in selected databases," British Journal of Educational Technology, vol. 47, no. 6, pp. 1006-1019, 2015.

[7] L. Briz-Ponce, J. A. Juanes-Méndez, F. J. García-Peñalvo, and A. Pereira, "Effects of mobile learning in medical education: A counterfactual evaluation," Journal of Medical Systems, vol. 40, no. 6 , pp. 1-6, 2016.

[8] C. S. Wang, Y. L. Jeng, and Y. M. Huang, "What influences teachers to continue using cloud services? The role of facilitating conditions and social influence," The Electronic Library, vol. 35, no. 3, 2017.

[9] L. W. Hsu, "Modelling determinants for the integration of web 2.0 technologies into hospitality education: A Taiwanese case," The Asia-Pacific Education Researcher, vol. 24, no. 4, pp. 625-633, 2015.

[10] D. Harmon, E. Kalmar, and J. Burgoon, "Development and implementation of a novel integrated anatomical sciences mobile app for medical students," The FASEB Journal, vol. 30 (1 Supplement), pp. 568-14, 2016.

[11] A. Tarhini, M. Hassouna, M. S. Abbasi, and J. Orozco, "Towards the acceptance of RSS to support learning: An empirical study to validate the technology acceptance model in Lebanon," Electronic Journal of e-Learning, vol. 13, no. 1, pp. 30-41, 2015.

[12] T. S. Teo, V. K. Lim, and R. Y. Lai, "Intrinsic and extrinsic motivation in Internet usage,” Omega, vol. 27, no. 1, pp. 25-37, 1999.

[13] M. H. Fagan, S. Neill, and B. R. Wooldridge, "Exploring the intention to use computers: An empirical investigation of the role of intrinsic motivation, extrinsic motivation, and perceived ease of use," Journal of Computer Information Systems, vol. 48, no. 3, pp. 31-37, 2008.

[14] T. Baum, "Skills and training for the hospitality sector: A review of issues," Journal of Vocational Education and Training, vol. 54, no. 3, pp. 343-364, 2002.

[15] S. C. Wong and P. C. Lee, "Competencies of training professionals in the Hong Kong hotel industry," Journal of Human Resources in Hospitality \& Tourism, vol. 16, no. 4, pp. 1-17, 2017.

[16] W. H. Ko, "The relationships among professional competence, job satisfaction and career development confidence for chefs in Taiwan," International Journal of Hospitality Management, vol. 31, no. 3, pp. 1004-1011, 2012.

[17] M. R. Weber, A. Crawford, J. Lee, and D. Dennison, "An exploratory analysis of soft skill competencies needed for the hospitality industry," Journal of Human Resources in Hospitality \& Tourism, vol. 12, no. 4, pp. 313-332, 2013.

[18] Guideline for curriculum design of hospitality program at secondary education level. (2009). Hospitality Education Center, Ministry of Education, Taiwan. [Online]. Available: http://vtedu.mt.ntnu.edu.tw/vtedu/files/doc/7/_8_.pdf

[19] C.-K. Chang and C.-K. Hsu, "A mobile-assisted synchronously collaborative translation-annotation system for English as a foreign language (EFL) reading comprehension," Computer Assisted Language Learning, vol. 24, no. 2, pp. 155-180, 2011.

[20] R. Saadé and B. Bahli, "The impact of cognitive absorption on perceived usefulness and perceived ease of use in on-line learning: An extension of the technology acceptance model," Information and Management, vol. 42, no. 2, pp. 317-327, 2005.

[21] R. A. Sánchez and A. D. Hueros, "Motivational factors that influence the acceptance of Moodle using TAM," Computers in Human Behavior, vol. 26, no. 6, pp. 1632-1640, 2010.

[22] Y. H. Wang, "Integrating self-paced mobile learning into language instruction: impact on reading comprehension and learner satisfaction,' Interactive Learning Environments, vol. 25, no. 3, pp. 397-411, 2017.

[23] F. D. Davis, R. P. Bagozzi, and P. R. Warshaw, "User acceptance of computer technology: A comparison of two theoretical models," Management Science, vol. 35, no. 8, pp. 982-1003, 1989.
[24] B. Szajna, "Empirical evaluation of the revised technology acceptance model," Management Science, vol. 42, no. 1, pp. 85-92. 1996.

[25] L. Hsu, "Diffusion of innovation and use of technology in hospitality education: An empirical assessment with multilevel analyses of learning effectiveness," The Asia-Pacific Education Researcher, vol 25, no. 1, pp. 135-145, 2016.

[26] A. Alenezi, "Checking on preferential choices of e-learning \& M-learning: A case study of Northern Border University, Saudi Arabia," International Journal of Emerging Technologies in Learning (iJET), vol. 12, no. 05, pp. 98-116, 2017.

[27] O. K. Boyinbode, O. C. Agbonifo, and A. Ogundare, "Supporting mobile learning with WhatsApp based on media richness," Circulation in Computer Science, vol. 2, no. 3, pp. 37-46, 2017.

[28] M. C. Caniëls, H. K. Lenaerts, C. J. Gelderman, and J. Jansen, "Explaining the internet usage of SMEs: The impact of market orientation, behavioural norms, motivation and technology acceptance," Internet Research, vol. 25, no. 3, pp. 358-377, 2015.

[29] Y.-W. Liao, Y.-M. Huang, H.-C. Chen, and S.-H. Huang, "Exploring the antecedents of collaborative learning performance over social networking sites in a ubiquitous learning context," Computers in Human Behavior, vol. 43, pp. 313-323, 2015.

[30] H. H. Chung, S. C. Chen, and M. H. Kuo, "A study of EFL college students' acceptance of mobile learning," Procedia-Social and Behavioral Sciences, vol. 176, pp. 333-339, 2015.

[31] L. W. Hsu, "EFL learners' acceptance of technology in a computer-assisted language learning (CALL) context: The role of intrinsic-extrinsic motivation in English learning," International Journal of Information and Education Technology, vol. 7, no. 9, pp. 679, 2017.

[32] M. T. Tai, N. C. Cheng, and K. S. Chen, "Understanding Online Group Buying Intention: The Roles of Sense of Virtual Community and Technology Acceptance Factors," Total Quality Management \& Business Excellence, vol. 22, no. 10, pp. 1091-1104, 2011.

[33] A. Bhattacherjee, "Understanding Information Systems Continuance: An Expectation-confirmation Model, " MIS Quarterly, vol. 25, no. 3, pp. 351-370, 2001.

[34] S. Chauhan, "A meta-analysis of the impact of technology on learning effectiveness of elementary students," Computers \& Education, vol. 105, pp. 14-30, 2017.

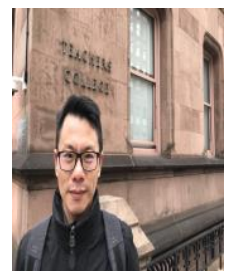

Liwei Hsu is a professor at the Graduate Institute of Hospitality, National Kaohsiung University of Hospitality and Tourism. Professor Hsu earned his doctorate in education at the University of Southern California, Los Angeles, USA. His current research interests include CALL as well as the application of ICT in hospitality education.

$\mathrm{He}$ is currently the dean of hospitality management in National Kaohsiung University of Hospitality and Tourism, Kaohsiung City, Taiwan. He has published articles in many peer-reviewed journals, including Computer Assisted Language Learning and the Australasian Journal of Educational Technology.

Professor Hsu is also a member of SIG for Hospitality Education Research under the supervision of the Ministry of Science and Technology of Taiwan.

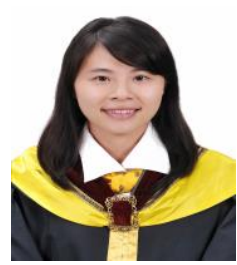

Chia-Wen Chen graduated from the Graduate Program of Hospitality Education, National Kaohsiung University of Hospitality and Tourism She is currently a research assistant at National Kaohsiung University of Hospitality and Tourism. 